developed. Through multiple PDSA cycles, we designed and tested a prototype inreach process. We then operationalized this process for patients admitted to the hospital medicine service, and focused on weekly failures to achieve process reliability.

Results Assessments of care gaps increased from $0 \%$ to $88 \%$ by the end of December 2018. The percentage of care gap resolution has increased from $30 \%$ to $40 \%$.

Conclusions Using QI methods, a new process to help improve population health for children can be successfully implemented outside of the traditional domain of primary care.

\section{IMPROVING HANDOFF EFFICIENCY IN THE PEDIATRIC INTENSIVE CARE UNIT}

${ }^{1}$ Callum Rowe, ${ }^{2}$ Jessica Signoff, ${ }^{2} J$ JoAnn Natale. ${ }^{1}$ University of California, Davis School of Medicine, USA; ${ }^{2}$ University of California, Davis Health, Department of Pediatrics, USA

\subsection{6/bmjoq-2019-ihi.19}

Background Pediatric Intensive Care Unit (PICU) handoffs are vital to safe patient care. Lengthy and inefficient handoffs can cause delayed patient care and faculty dissatisfaction. In our university-based tertiary care PICU, observation of handoffs showed that only $50 \%$ concluded by schedulded time. In a survey, only $40 \%$ of PICU faculty expressed satisfaction with this handoff process.

Objectives We sought to improve efficiency of handoffs, with the aim of at least $75 \%$ of attending evening handoffs completed on time after project completion. Using Lean Six Sigma methodology, a quality improvement project to improve efficiency of evening attending handoff was implemented in a tertiary care PICU.

Methods Pre-intervention processes were studied using workflow mapping and data collection using observation and selfreported handoff times. Root causes of inefficiencies were identified, and low-effort, high-benefit interventions were sequentially implemented: 1) minimizing interruptions from PICU nurses during handoff; 2) ensuring on-time handoff initiation; 3) discussing expectations of efficient handoff at weekly PICU faculty meetings.

Results After implementation of lean management principles, evening faculty handoff efficiency was improved; $85 \%$ of handoffs were completed on-time. In addition, faculty satisfaction with the handoff process increased. The PICU census was monitored throughout the intervention period. There was no correlation between increased census and longer handoff duration.

Conclusions We successfully improved efficiency of the handoff process. While implemenataions required buy-in from

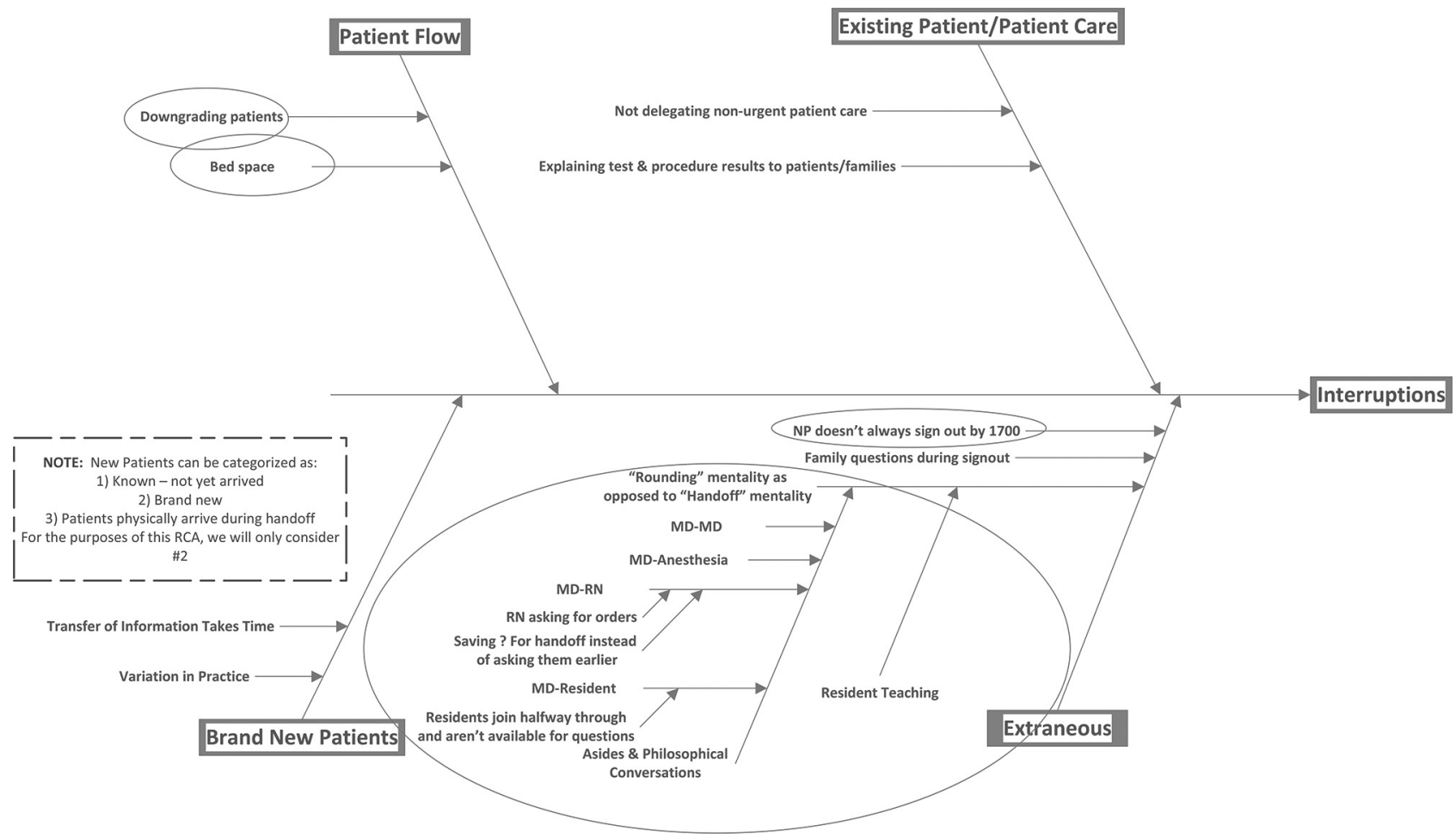

Abstract 19 Figure 1 


\section{End Time of Handoff Rounds}

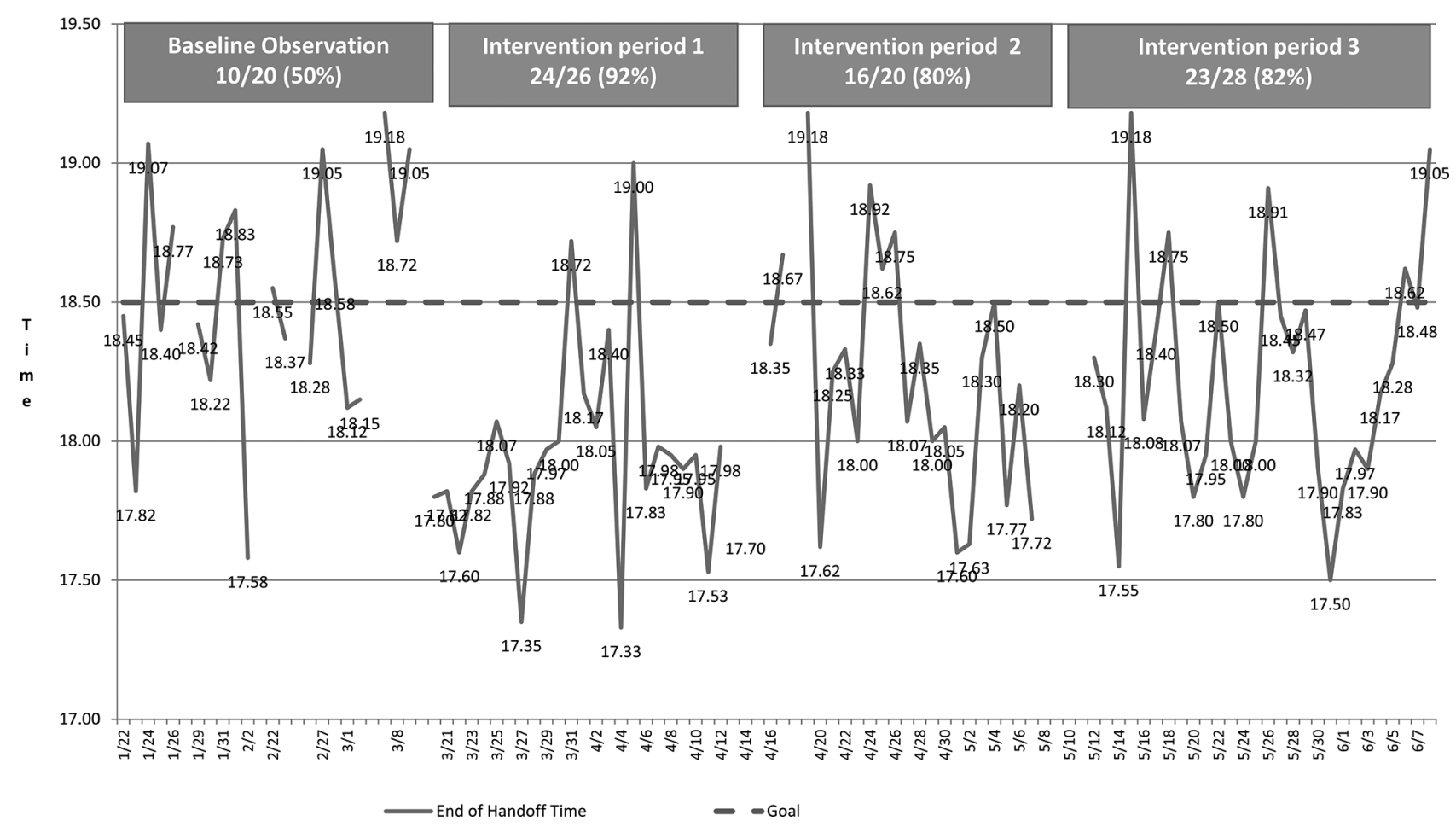

Abstract 19 Figure 2

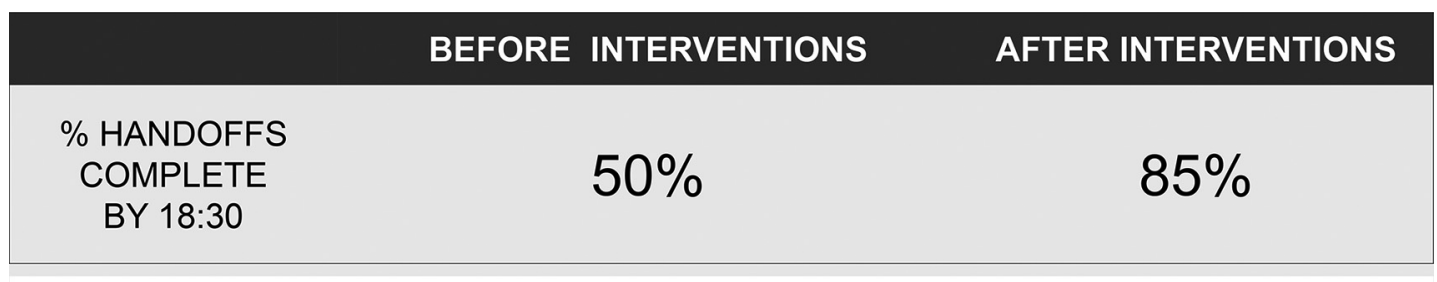

End Time of Handoff Rounds

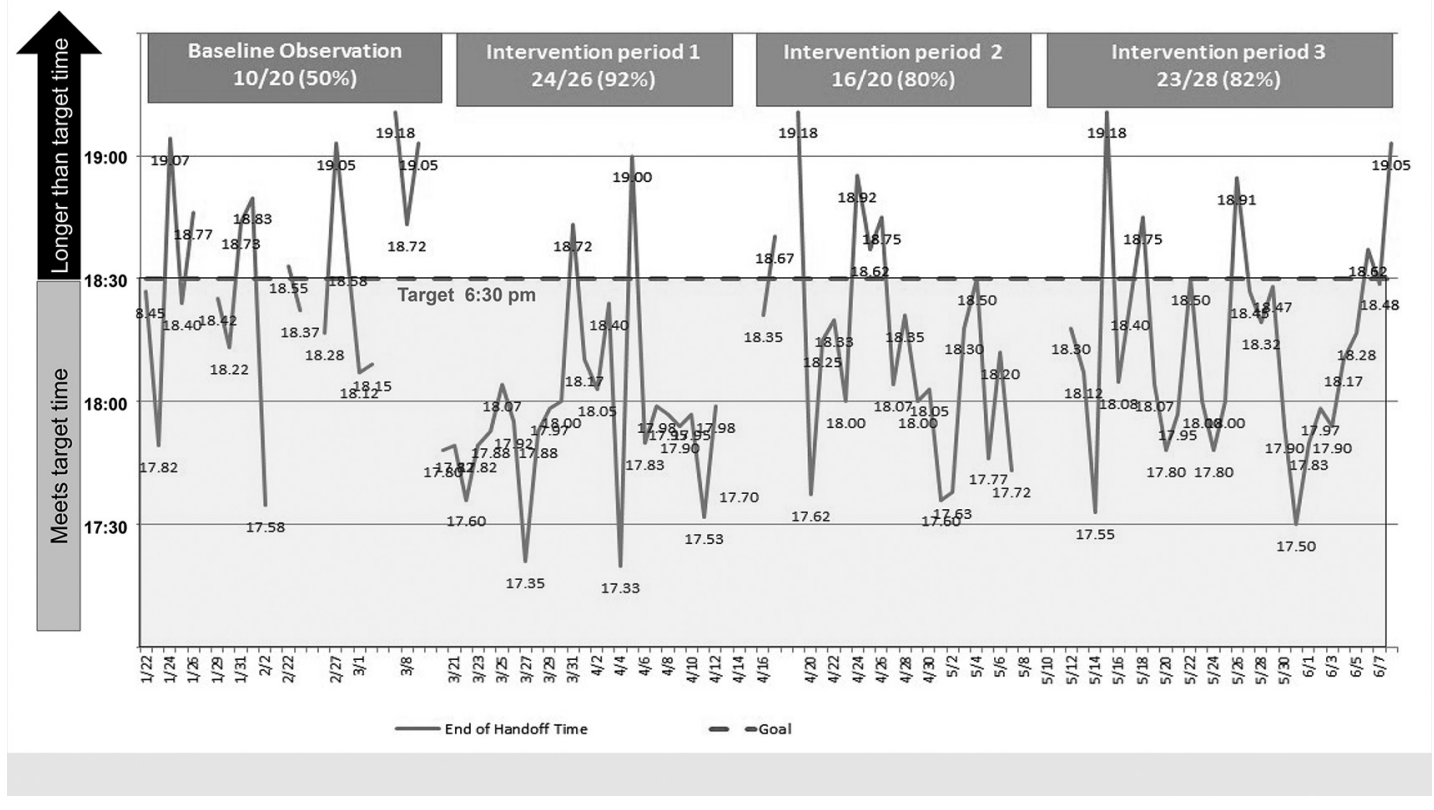

Abstract 19 Figure 3 Graphical display showing end of handoff time during the study period 
stakeholders, they resulted in increased faculty satisfaction with relatively low cost and effort. Continued assessment is necessary to maintain the improvements. Future studies could investigate any association between the imporved efficiency, patient safety and outcomes.

\section{LINKING PEDIATRIC PRIMARY CARE AND SYSTEMS: DULCE EXPANSION VIA QUALITY IMPROVEMENT ADVANCES PATIENT-CENTERED CARE AND ADDRESSES HEALTH-RELATED SOCIAL NEEDS}

${ }^{1}$ MaryCatherine Arbour, ${ }^{2}$ Baraka Floyd, ${ }^{3}$ Samantha Morton, ${ }^{4}$ Sidney Atwood, ${ }^{5}$ Stephanie Doyle, ${ }^{5}$ Patsy Hampton, ${ }^{6}$ Robert Sege. ${ }^{1}$ Harvard Medical School, USA; ${ }^{2}$ Stanford School of Medicine, USA; ${ }^{3}$ MLPB, USA; ${ }^{4}$ Brigham and Women's Hospital, USA; ${ }^{5}$ Center for the STudy of Social Policy, USA; ${ }^{6}$ Tufts Medical Center, USA

\subsection{6/bmjoq-2019-ihi.20}

Background American Academy of Pediatrics Bright Futures ${ }^{\mathrm{TM}}$ 4th edition health supervision guidelines prioritize screening for and addressing health-related social needs (HRSN) in the patient centered medical home. Time constraints, lack of knowledge of resources, and other priorities make implement- ing these recommendations challenging. DULCE (Developmental Understanding and Legal Collaboration for Everyone) is an evidence-based intervention that embeds a community health worker in an interdisciplinary team that includes a pediatrician, mental health clinician, legal partner, and early childhood system representative to screen for and address HRSN, maternal depression, intimate partner violence, and to build on family strengths.

Objectives To adapt DULCE at five sites across the U.S., so that by July $31,2018,75 \%$ of families receive all routine healthcare (RHC) visits on time, 95\% are screened for seven HRSN, and $90 \%$ of families with concrete supports needs and $75 \%$ of families with maternal depression or intimate partner violence needs receive support.

Methods We used a 19-month technical assistance approach with QI coaching.

Results The percent of families that completed all RHC visits on time increased from $46 \%$ to $65 \%$. More than $94 \%$ of families were screened for HRSNs, $70 \%$ had one or more positive screen, and $88 \%$ of those were provided resources. Most prevalent needs were for financial assistance (53\%), food (46\%), depression support (14\%) and housing stabilization $(13 \%)$.

\section{SMART Aims}

By the infant's 6 month visit, families will

1) Receive all Bright FuturesTM recommended routine healthcare visits on time

$75 \%$ of children will get all RHC visits on time $80 \%$ of expected $R H C$ visits occur on time

2) Receive high-quality, family-centered routine healthcare visits*

in $95 \%$ of RHC visits, the FS will use Touchpoints principles

3) Connect to supports during the intervention \& beyond**

90\% of families who screen positive for barriers to concrete supports will access supports that they want and for which they are eligible

$75 \%$ of families with maternal depression or IPV needs receive support

* characterized by effective partnerships with the care team, family-centered communication, developmental promotion, education about development through teachable moments, and strategies to promote protective factors

**this includes families that got support during the intervention and those that had ongoing needs at the end of the intervention and were connected w ongoing support post-intervention
Primary Drivers

\begin{tabular}{|c|c|}
\hline $\begin{array}{l}\text { Comprehensive care } \\
\text { enriched by FS } \\
\text { engagement during } \\
\text { and between RHC } \\
\text { visits }\end{array}$ & \multirow{2}{*}{$\begin{array}{l}\text { - FS present during RHC visit } \\
\text { - DULCE curricular activities (brain messages, handouts, etc) } \\
\text { - Additional support (home visit, telephone, text, email, etc) } \\
\text { - FS integrated as essential member of primary care team (included in } \\
\text { all team meetings, access to EHR, etc) } \\
\text { - Clinic protocols for enrollment, integrating FS into workflow } \\
\text { - Formal, regular, face to face supervision for FS, including a) } \\
\text { administrative supervision and b) individual reflective supervision }\end{array}$} \\
\hline \multirow{2}{*}{$\begin{array}{l}\text { Systematic } \\
\text { identification of } \\
\text { family strengths }\end{array}$} & \\
\hline & \multirow{2}{*}{$\begin{array}{l}\text { - Identification and reinforcement of families' protective factors } \\
\text { - Focus on, enhance parent-child attachment and attunement } \\
\text { - Recognition of the unique contribution of each infant and } \\
\text { anticipation of periods of change and stress } \\
\text { - Support of parental process of mastery } \\
\text { - Identification, reinforcement of families' social connections }\end{array}$} \\
\hline \multirow{2}{*}{$\begin{array}{c}\text { Systematic } \\
\text { identification of social } \\
\text { determinants of } \\
\text { health and family-led } \\
\text { problem-solving }\end{array}$} & \\
\hline & - Protocols, procedures for communication with team about identified \\
\hline \multirow{2}{*}{$\begin{array}{l}\text { Interdisciplinary } \\
\text { team that conducts } \\
\text { weekly case review } \\
\text { and ongoing } \\
\text { collaboration to } \\
\text { inform care } \\
\end{array}$} & $\begin{array}{l}\text { MH needs, safety assessment, and intervention planning } \\
\text { - Team-based, role-appropriate, family-centered support to access } \\
\text { services and benefits for mental and behavioral health needs } \\
\text { - Mental health lead reflective supervision of FS } \\
\text { - Identification of opportunities to effect policy change and/or systems } \\
\text { improvements }\end{array}$ \\
\hline & - Includes a legal advocate, MH lead and early childhood system \\
\hline \multirow{2}{*}{$\begin{array}{l}\text { Clinical care for } \\
\text { infants is embedded } \\
\text { in the local early } \\
\text { childhood system }\end{array}$} & DIR \\
\hline & $\begin{array}{l}\text { - Multi-disciplinary teams identify system gaps and families' } \\
\text { unaddressed needs to 1) engage the EC system to redress DULCE } \\
\text { families' needs and 2) use data to inform early childhood policy }\end{array}$ \\
\hline \multirow{2}{*}{$\begin{array}{l}\text { Families as partners } \\
\text { in DULCE design and } \\
\text { implementation }\end{array}$} & $\begin{array}{l}\text { - The designated early childhood system lead serves as the local } \\
\text { backbone organization for DULCE }\end{array}$ \\
\hline & - Dulce teams create and sustain forums for families to provide \\
\hline \multirow{2}{*}{$\begin{array}{l}\text { Continuous quality } \\
\text { improvement: data- } \\
\text { driven adaptation }\end{array}$} & feedback \& share ideas \\
\hline & $\begin{array}{l}\text { - Iterative, data-driven adaptation to improve DULCE implementation } \\
\text { and outcomes for children, families, and interdisciplinary partners }\end{array}$ \\
\hline
\end{tabular}

